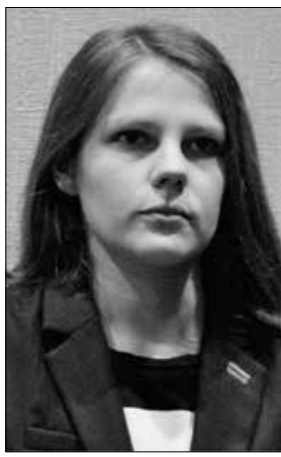

https://doi.org/10.24101/logos.2020.20

Gauta 20200123

\title{
MIGLE் MUNDERZBAKAITE்
}

Vytauto Didžiojo universitetas, Lietuva

Vytautas Magnus University, Lithuania

\section{LITERATÜROS KÜRINIŲ ADAPTACIJOS: FRANZO KAFKOS KÜRINIŲ ATVEJAI}

\author{
Adaptations of Literary Works: Cases of Franz Kafka
}

\begin{abstract}
SUMMARY
The article analyzes the examples of adaptations of literary works in different media from the perspective of adaptation studies. The focus is placed on the transformation and interpretation of the narrative, characters, images, symbols, space, time of the adapted work in other media. The aim is to identify intertexts and to show the dialogism of the interpretations created by the directors in the general context of adaptation of the same literary work. Two works by the writer Franz Kafka were selected for analysis. The first one is a short story, Metamorphosis (1915). The adaptions are the play, Judgment: Metamorphosis (2012), by the Lithuanian director Paulius Ignatavičius and a film, Franz Kafka. Wonderful Life (1993), by the Scottish director Peter Capaldi. These directors adapt the novel in different ways. Ignatavičius combines it with other works by F. Kafka, and Capaldi looks back at the writer's biography and the process of writing a short story. The second work by Kafka is the novel, The Castle (1924). Its first adaptation is as a contemporary opera by German independent opera company NOVOFLOT and director Sven Holm - The Castle (Das Schloss, 2013). Here the novel is combined with Franz Schubert's music, The novel's second adaption is a film by Austrian filmmaker Michael Haneke entitled The Castle (Das Schloß, 1997). It focuses on transposing all elements of the novel's narrative into cinematic media.
\end{abstract}

\section{SANTRAUKA}

Šiame straipsnyje iš adaptacijos studiju perspektyvos analizuojami literatūros kūrinių adaptaciju pavyzdžiai ¡̇vairiose medijose. Daugiausiai dėmesio skiriama adaptuojamo kūrinio naratyvo elementų transformavimui ir interpretavimui kitoje medijoje. Siekiama identifikuoti intertekstus, parodyti režisierių sukurtų interpretacijų dialogiškumą bendrame to paties kūrinio adaptavimo kontekste. Analizei pasirinkti du rašytojo Franzo Kafkos kūriniai. Novelè "Metamorfozė", jos adaptacijos - lietuvių režisieriaus Pauliaus Ignatavičiaus spektaklis „Nuosprendis: metamorfozè" (2012) ir škotų režisieriaus Peterio Capaldi filmas „Franz Kafka. Nuos-

RAKTAŽODŽIAI: adaptacija, naratyvas, Franzas Kafka, intermedialumas, dialogiškumas.

KEY WORDS: adaptation, narrative, Franz Kafka, intermediality, dialogism. 
tabus gyvenimas“ („Franz Kafka's. It's a Wonderful Life“, 1993). Šie režisieriai skirtingais būdais adaptuoja novelę - susieja su kitais F. Kafkos kūriniais (P. Ignatavičius), atsigręžia į pati rašytoją bei novelès kūrimo procesą (P. Capaldi). Kitas kūrinys - romanas "Pilis". Jo adaptacijos - vokiečių nepriklausomos operos kompanijos "NOVOFLOT“ ir režisieriaus Sveno Holmo šiuolaikinè opera „Pilis" ("Das Schloss", 2013), kurioje romanas susiejamas su Franzo Schuberto muzika, ir austrų kino režisieriaus Michaelio Haneke's filmas "Pilis" („Das Schloß", 1997 m.), siekiantis perkelti visus romano naratyvo elementus į kino mediją.

\section{IVADAS}

Režisieriai austrų rašytojo Franzo Kafkos kūryba labiausiai domèjosi po Antrojo pasaulinio karo, tačiau dèmesys nemažèja iki šiol. Kuriamos jo kūrybos adaptacijos kino filmuose, dramos, šokio spektakliuose, operose. Sukurta vaizdo žaidimų, esama ir virtualios realybės adaptacijų.

Per pastaruosius kelis dešimtmečius Lietuvoje taip pat sukurta F. Kafkos kūrybos adaptacijų. 1990 m. režisieriaus Sauliaus Varno spektaklis pagal romaną „Procesas". Šis Kafkos kūrinys 1994 m. Algimanto Puipos buvo adaptuotas ir kine. Pagal rašytojo noveles Paulius Ignatavičius pastatė spektakli „Nuosprendis: Metamorfozé" (2012). Jis taip pat yra sukūręs ir dar vieną F. Kafkos kūryba paremtą spektaklị "Kova“ (2009). 2015 m. režisierius E. Nekrošius teatro scenoje sukūrè novelès „Bado meistras“ adaptacija, kurioje ryški menininko, teatro (au- to)refleksija. Choreografas Taurūnas Baužas ir režisierè Kristina Jasiukonyte pastatè šiuolaikinio šokio spektaklį „Pradžioje buvo Kafka“ (2015), kurio îkvėpimo šaltiniu tapo kūrinys „Laiškas tèvui“.

Platesniame medijų ir F. Kafkos interpretaciju kontekste šios adaptacijos beveik neanalizuotos. Tekstinius santykius, adaptacijas tirianti Regina Schober akcentuoja besiformuojanti ryšiu procesą tarp skirtingu to paties kūrinio adaptaciju. Šiame straipsnyje siekiama panagrinèti bent dali lietuviškų F. Kafkos kūrybos interpretacijų, nustatyti santyki su tarptautiniu mastu žinomomis rašytojo kūrinių interpretacijomis.

Toliau analizuojamos itin skirtingos dvieju F. Kafkos kūrinių - „Metamorfozès" (1915) ir „Pilis" (kūrinys nebaigtas, išleistas 1926 m.) - adaptacijos dramos teatre (P. Ignatavičius), operoje (S. Holmas) ir kine (M. Haneke, P. Capaldi).

\section{F. KAFKOS KŪRINIŲ JUNGTYS}

Pauliaus Ignatavičiaus spektaklyje „Nuosprendis: metamorfozé “ apjungiami trys F. Kafkos kūriniai. Režisierius teigia:

Kūriniuose, kuriuos pasirinkau inscenizacijai: Nuosprendis, Metamorfozė ir Laiškas tèvui, itin aštriai nagrinèjami tèvo ir sūnaus santykiai. I paviršiu iškeliamas amžino kautynių lauko, kurị mes vadiname šeima, absurdas. Pats Franzas Kafka parašè ilgą laišką savo tèvui, bet jo išsiųsti taip ir nepajègè, vèliau jis išspausdintas kaip atskiras kūrinys. Jis niekada neištrūko iš tèvo nelaisvès, bet tai jo kūrybai suteikè tam tikrą vaizduotès varikli, $<\ldots>$ jègą bei vidinį konfliktą<...>. Aš pasirin- 
kau būtent šiuos kūrinius siekdamas suprasti tai, kas yra pats sudètingiausias ir pažeidžiamiausias dalykas pasaulyje: šeima (Ignatavičius 2012).

P. Ignatavičiaus spektaklyje kūriniai jungiami keičiant bei pritaikant ir pačius personažus naujam pasakojimui. Šiame spektaklyje veikia keturi režisieriaus pasirinkti personažai: Gregoras (vaid. Josif Baliukevič), tèvas (vaid. Eugenijus Ignatavičius), Grètè (vaid. Eglè Lekstutytè), moteris (vaid. Indrè Patkauskaitè). Visiems tenka užduotis kurti keliasluoksnius personažus. Spektaklis pradedamas „Nuosprendžiu“, vèliau įterpiami fragmentai iš "Laiško tèvui," pereinama i „Metamorfozę", o pabaigoje laukia „Laiško tèvui" skaitymas. Personažo Gregoro biografiją bei charakterio ypatybes sudaro ir "Nuosprendžio" veikèjo Georgo Bendemano gyvenimas, ir netikèto izvykio ištikto Gregoro Zamzos problemos.

Svarbu tai, jog Gregorą galima laikyti ir ikūnijančiu pati autorių F. Kafka, nes jis palieka parašytą laišką tèvui, o tai yra rašytojo kūrinys, kurio nepasiektas adresatas buvo jo tėvas. Scenoje kuriamas Gregoro personažas vienu metu nori pasirodyti laimingas, kitu tampa nervingas, nusivylęs; kai kuriose scenose dèl visko aršiai kaltina tėva, kitose ieško pateisinimų. Šios analizès centre esančiai „Metamorfozei“ toks personažų apjungimas suteikia dar daugiau emocinio krūvio, personažai tampa sudètingesni, prieštaringesni.

Spektaklyje nèra vizualios Gregoro transformacijos i vabala, tačiau, išnaudojant teatro medijos galimybes, aiškiu nuorodu i i ivykusią metamorfozę galime rasti - tai vidiniai, psichologiniai poky- čiai ir dialogai apie Gregoro sumušimą bei smurto įrankius.

Tèvo personažas apima dviejų kūrinių tévo istorijas, apibendrinus jis atstovauja klausytojo pozicijai. Jis, kaip būdinga Kafkai, griežtas bei šaltas pokalbiuose su sūnumi, o galiausiai parodomas kaip nusivylęs ne Gregoru, bet savo paties gyvenimu.

Grètès personažas nuosekliai seka „Metamorfozèje“ rašytojo sukurtu Gregoro sesers portretu, ji iš dalies įkūnija ir Gregoro sužadètinę. Personažas, ịvardintas kaip Moteris, atlieka „Metamorfozès" veikejjo prokuristo funkciją. Vèliau ši veikejja kinta, tampa griežta tardytoja, intensyviai bandančia išsiaiškinti nusikaltimą.

Scenoje suformuotos dvi erdvès Zamsų butas ir teismo salè. Scenovaizdyje vos keletas elementų: metalinès kèdès, stalas, šviestuvai. Apšvietimo kaita prisideda prie spektaklio ritmo bei nuotaikos. Naudojama projekcija, kurioje žemèlapis su visuose žemynuose esančiu tévo vardu - tai nurodo ị kūrinị „Laiškas tèvui", kuriame akcentuojamas nesugebejjimas pabėgti nuo tèvo ịtakos.

Adaptacijoje kūrinių jungimas patvirtino mintị, kad rašytojo kūriniai susiję su jo paties išgyvenimais, dauguma ju analizuoja artimas viena kitai temas: šeimos, sūnaus ir tèvo santykius bei žmogư, dèl aplinkos įtakos gyvenantị ne savo gyvenimą.

Šiame spektaklyje galima kalbèti ir apie dvejopa pabaigą. Pabaigoje, kaip ir Kafkos kūrinyje, Gregoras miršta, tačiau tèvui paliekamas Gregoro laiškas, kuri jis gali perskaityti, priešingai nei nutiko dèl F. Kafkos laiško. Čia jam suteikiama galimybė išgirsti, ką galvojo jo sūnus, ko neišdrįso pasakyti jų konfliktų metu. 


\section{„METAMORFOZĖS“ KŪRYBINIO PROCESO ADAPTACIJA}

Škotų režisieriaus Peterio Capaldi trumpametražiame filme „Franzas Kafka. Nuostabus gyvenimas" kuriamas netikètas ryšys tarp F. Kafkos kūrybinio proceso ir filmo "Nuostabus gyvenimas" („It's a Wonderful Life“, 1946, rež. Frank Capra). F. Capra'os filmas taip pat yra rašytojo P. V. D. Sterno literatūros kūrinio "Didžiausia dovana“ („The Greatest Gift", 1943) adaptacija. P. Capaldi, už ši filmą nominuotas Oskarui, teigè: būnant sąžiningiems, šis filmas yra krūva triuku, sujungtu, tikiuosi, stilingu ir lakios vaizduotès būdu“ (Woods 2013: 235).

Filme iprastų "Metamorfozès" personažų beveik nerasime. Net pagrindinis veikëjas Gregoras Zamsa (vaid. Crispinas Lettsas) vabalo pavidalu ir dainuojantis pasirodo tik filmo pabaigoje. Svarbiausiu personažu čia tampa kūrinio pasakotojas - autorius Franzas Kafka (vaid. Richardas E. Grantas). Ironiškai filme sprendžiamas rašytojui svarbus klausimas - kuo Gregoras tapo lemtingą rytą.

Filmo kūrejjai išnaudoja medijos galimybes, kad rašytojo vaizdiniu pasirodymas būtų netikètas, nenuspejjamas. Rašytojas parodomas kaip nervingas, užsidaręs savo niūriame, tamsiame kambaryje. Išlaikant F. Kafkai būdingą absurdo stilių, režisierius įtraukè keistus, netikètus personažus, kurie vis trukdo susikaupti ir priimti galutini sprendimą. Pavyzdžiui, nelauktai vis apsilankantis makabriškos išvaizdos ginklu pardavèjas. F. Kafka kenčia ir nuo nuolatos girdimo triukšmo, kurị sukelia mergaičiu šventinis vakarèlis, idiliška nuotaika primenantis "Nuostabuji gyvenimą".
Rašytojo įvaizdis kuriamas sekant jo biografijos žiniomis: „F. Kafka manè, jog rašytojui nevalia atsitraukti nuo rašomojo stalo, visuomenès, nes bendraudamas su kitais jis priverstas atsisakyti savojo aš” (Bajarūnienè 1997: 10).

F. Kafkos kūrybinių ieškojimų kambarys yra neįvardintoje pilyje, kurią kamera trumpai fiksuoja filmo pradžioje. Tai aliuzija i rašytojo romaną "Pilis". Rašytojo erdvè: tamsus kambarys su rašomuoju stalu bei menku apšvietimu kuria kontrastą šventinei kalėdinio vakarèlio atmosferai, esančiai už sienos. Galima įžvelgti ir vieną elementa, susiejantị „Metamorfozès“ veikëją Gregorą su šios adaptacijos herojumi. Tai - langas, pro kuri gyvenimą bando stebèti vabalu pavirtęs Gregoras ir i kuri vis krypsta rašytojo žvilgsnis.

P. Capaldi savo filme analizavo galimą F. Kafkos kūrybini gyvenimą, su humoru pateike įvairias personažo transformacijos versijas, itraukè kito filmo fragmentus, vizualumui panaudojo Kafkos mėgstamą absurdą bei kitus jo kūrybos akcentus. İdomu tai, kad tarp visiškai skirtingų kūrinių - „Metamorfozès" ir filmo "Nuostabus gyvenimas" galima atrasti tam tikru ryšių. Abieju kūriniu pagrindiniai veikèjai jaučia gyvenantys ne savo gyvenimą. George'as Bailey'us turëjo didelių užmoju išvykti iš mažo, slegiančio miestelio, bet ji sulaiko tèvo paliktas bankas, kuriame jis pradeda dirbti iš pareigos šeimai. Kafkos veikejjas, kaip ir pats rašytojas, dirba nemègstamus darbus. Svarbiausia šiu kūriniu jungtis yra pasikeitimas - metamorfozè. George'as, sutikęs angelą, pa- 
tenka i kitoki gyvenima, kuriame jo nèra, jis bando bendrauti, bet visi ji atstumia, nepažista. Gregorą taip pat ištinka po- kytis. Žinoma, Kafkos veikëjui šis virsmas ì vabalą baigiasi mirtimi, o minètas veikëjas gauna antrą šansą.

\section{NUOSEKLI TRANSFORMACIJA ! KINO MEDIJA}

F. Kafkos romaną „Pilis“ kinui adaptavo žymus austrų režisierius, scenaristas Michaelis Haneke. Kritikai dažnai apibūdina ji kaip kurstytoja pabrèždami, kad Haneke, kaip niekas kitas šiuolaikiniame kine, geba paprastu, stačiokišku būdu prisiliesti prie problemos, panardinti į socialini, politinị ir kultūrinị kontekstą (Foundas 2001).

Režisierius: „,Pilis' buvo sukurta televizijai ir aš matau aiškią skirti tarp televizinès versijos ir kino filmo. Filmai televizijai turi būti daug artimesni knygai todèl, kad tikslas - auditoriją paskatinti kūrini perskaityti savarankiškai“" (ten pat). Anot F. F. Croce'o, buvo tik laiko klausimas, kada F. Kafkos ir M. Haneke's, dviejų atsidavusių mizantropų, atšiaurios pasaulèžiūros kūrèju, keliai susikirs (ten pat).

Anot Michell Woods, M. Haneke's "didžiojo ekrano" kino filmų autorinis stilius ir jo elementai akivaizdūs ir šiame filme, jie kuria dialogą F. Kafkos romano forma (Woods 2013: 201). Su filmą pristatančiais titrais ekrane parodomas stilizuotas kaimo su kalnu žemèlapis. Filmo pradžioje ekrane matome pasirodantị K. (vaid. Ulrichas Mühe), kuris atrodo lyg šių laikų keliautojas: vilnonè kepurè, striuke, kuprinè, o pilies kaimo provincialų baras atrodo tarsi sustingęs laike. Adaptacija išlaiko rašytojo kūrinio struktūrą. Filmas apima visus romano įvykius bei personažus, režisieriui svarbi kiekviena kūrinio detalè.
„M. Haneke's adaptacija vizualiai atspindi F. Kafkos romano atmosferą; mes matome, kaip K. kovoja su jègos struktūromis ir atremia ìvairius kaimo gyventoju žvilgsnius. K. susiduria su nesusikalbejjimu, apmirimu ir susvetimèjimu“ (ten pat). Visa veikejų komunikacija paremta nepaaiškinamomis taisyklemis ir nuolatine baime, vis kalbama apie kažkoki aukštesni ir ịtakingesni kita.

Atkuriant rašytojo aprašytas erdves, vyraujančią atmosfera, daugelis erdviu, išskyrus kaimo užeigas bei mokyklas, pasižymi gana blankiu apšvietimu. Dažnai galima matyti nestabilius laiptus, vos ¡ž̌iūrimus namo užkaborius. Išorès erdvè nekuria kontrasto, dažniausiai scenose matomas arba vakaras, arba pilka, niūri diena. Sninga beveik nuolat, kai tik herojus išeina iš kokios nors namu erdvès. Monotoniškas sniegas ir stiprus vejjas yra toks, kad herojus vos geba judèti pirmyn. K. tokioje aplinkoje atrodo dar beviltiškiau, pūga, prieš kurią reikia atsilaikyti fiziškai, primena kitas ji užgriuvusias problemas, kurioms išspręsti reikia dar stipresniu jègų.

Siekdamas atspindèti fragmentišką romano pobūdì, M. Haneke naudoja juodus ekranus, "sulaužančius" sekas ir scenas: , $<\ldots . .>$ matomi ir nematomi teminiai aspektai juoduose ekranuose atspindi viską apimančią ardomajją komunikacija, prabėgančią per visą istoriją" (Smith 2009: 39). Autorè Carrie Smith kaip pa- 
vyzdžius pateikia absurdišką padètị veikëjui K. kuriančias situacijas. Jis gauna laiškus, kuriuos vos gali iššifruoti; K. padejejjai kalba vienas per kitą painiais pasikartojimais; dokumentas, liudijantis K. kvietimo i pili istorija prarastas absurdiškoje krūvoje kitų dokumentų.

Režisierius bando komunikuoti su žiūrovu.

Per juodą ekraną žiūrovas patiria komunikacijos sunkumus siekdamas patekti i pilį; žiūrovo stebejimo patirtis trukdoma arba suskaidoma ir žiūrovas turi kovoti, kad pasakojimas liktu nepaliestas, nesugriautas. Trukdantis juodas ekranas verčia žiūrovus ịsitraukti i a abejones dèl vaizduojamos tiesos ir užpildyti tarpus, spragas istorijoje (ten pat).

Sprendimas artimas ir F. Kafkos kūrybai, kurioje skaitytojas dažnai paliekamas nežinioje, apmąstymuose.

Tai atskleidžia kūrinio naratyvinès struktūros fragmentiškumą (žinoma, kūrinys yra trumpinamas ir dèl techniniu priežasčių). Dèl šio sprendimo adaptaciją iš dalies galima priskirti Th. Leitcho siūlomam suspaudimo (compression) adaptacijų tipui, kai atsisakoma kai kurių kūrinio fragmentų (Leitch 2007: 96).

Tokiu būdu pasakojimas žiūrovui turètų tapti aiškesnis. Tačiau rodant visas, net ir smulkiausias scenas, pagreitintai, fragmentiškai prabégus K. nueitą beviltišką kelia, kai kurios scenos praranda tekste pamažu auginamą įtampą.

M. Haneke's filme svarbus operatoriaus darbas: dažnai pasitelkiami stambūs planai, kartais personažas vaizduojamas lyg neittelpantis į kadra, veikèjai, užimantys aukštesnes pareigas, neretai filmuojami pasirenkant rakursą iš apačios, tokiu būdu sustiprinant jų tariamą reikšmingumą.

Visas filmas pasižymi specifine filmavimo ypatybe, veikèjas K., keliaudamas iš vieno taško i kita, siekdamas išsiaiškinti savo problemišką padètị, nuolatos tarsi vaikšto horizontalia linija - i dešinę arba i kairę, vienu metu sekamas kameros, kitu išnykstantis iš filmavimo lauko. Herojus absurdiškai vaikšto pirmyn atgal nepasiekdamas savo tikslo.

\section{MEDIJŲ IR KÜRINIŲ JUNGTYS}

Teatro NOVOFLOT ir režisieriaus Sveno Holmo sukurta romano adaptacija šiuolaikinëje operoje nuosekliai neseka F. Kafkos tekstu. Romano „Pilis“ pasakojimas jungiamas su Franzo Schuberto muzikinių kūrinių ciklu „Žiemos kelionè" (1828). Režisierius apie F. Kafkos kūrinio pasirinkimą sako: „Žinoma, Kafka nèra teatrališkas. O muzika yra nuolatinis judejjimas. Tai ir buvo priežastis pasirinkti. Šitie prieštaravimai ir buvo mūsų ìkvėpimas" (Holm 2016). Adapta- cijos analizès kontekste svarbu tai, jog F. Schuberto kūrinys taip pat yra ankstesnių poeto Wilhelmo Müllerio kūrinių adaptacija. Adaptacijoje šalia F. Kafkos teksto bei muzikos egzistuoja trečia itin svarbi dalis - scenografija, iliustratoriaus Ulricho Scheelo gyvai kuriami piešiniai.

Spektakliui būdingi trumpi tekstiniai intarpai, paremti romanu arba pristatantys ji. Išlaikant F. Kafkos romano tema, čia atliekamos laisvos interpretacijos: i kanceliarijų veiklą itraukiami vaikai, 
naujai interpretuojami personažai, kai kurie aktoriai scenoje kuria net po kelis personažus.

Anot spektaklio recenzijos autorès Noros Mansmann, režisierius parinko pagrindinę temą - K. atmetimą ir buvimą nuolatinëje atskirtyje (Mansmann 2013). Nepaisant kūrèju pasirinkimo laisvai interpretuoti romano teksta, spektaklyje esama scenų, vizualių nuorodų, akivaizdžiai nurodančių spektaklio įkvèpimo šaltini. Neretai matome F. Kafkos knyga, kuri vienais atvejais cituojama, kitais iš jos plěšomi lapai siekiant sudèlioti K. veiksmų schemą. Scenografija sukurta taip, kad reikiamoje scenoje ji gali būti suprantama kaip vaizduojanti pilies kanceliarija, o kitose scenose - pilies užeigą. Šalia vykstančio veiksmo naudojami U. Scheelo piešiniai: simboliai, ženklai, trumpos frazès, kurios apibūdina, reziumuoja vykstanti veiksmą. Pavyzdžiui: „Mums nereikia matininku“", ,K+Fryda“, ,Išmetimas iš užeigos", kaip ir M. Haneke's juodais ekranais, pasakojimas tarsi suskaidomas i smulkesnius fragmentus.

Sekant rašytojo kūriniuose fiksuojamais vaizdiniais, erdvè suformuota kaip slogi, suvaržanti. Jau spektaklio pradžioje scenos kamputyje matome spektaklio orkestra, kurio nariai grodami vos geba nekliudyti vienas kitam. Erdvès suspaudimui panaudojamos ir metalinès konstrukcijos, kurios veiksmo metu pamažu nusileidžia iš pradžių sulig aktorių ūgio, o vèliau uždengia jų veidus.

Svarbus ir žiūrovų ịtraukimas: praèjus dešimčiai minučių nuo spektaklio pradžios, žiūrovai pakviečiami persikelti i kitą erdvę. Publika spektaklyje pa- tenka i teatro scena, jos užkulisius ir ìsikuria pačiame paslaptingo kafkiškojo pasaulio viduryje. Žiūrovas tampa tarsi dar vienu pilies veikejju. Dèl techninių sprendimų žiūrovas sukasi kartu su K. personažu ir jam nutinkančiais įvykiais, tuo pat metu judèdamas kanceliarijos ir pilies užeigos erdvėmis. Toks pasirinkimas nurodo, kad žiūrovą siekiamas tapatinti su K., jam tarsi pasiūlomas atstumtojo vaidmuo.

Autorès N. Mansmann teigimu, pagrindinis personažas K. sudarytas iš trijų muzikos atlikèjų - aktorių. Esama ir teiginių, kad herojus spektaklio metu išsiskaido ne tik i šiuos tris, bet ir dar daugiau smulkesnių dalių - veikejjų. Tokia recenzentų nuomonè verčia daryti išvada, kad spektaklyje personažo skaidymasis rodo vis didejjanti ne tik pagrindinio veikejjo, bet ir kiekvieno gyventojo susvetimejjimo jausmą.

Visų spektaklio personažų apranga simboliška: „pilies atstovai ir kaimo gyventojai apsirengę ruda ir balta (tai vaikai, muzikantai ir piešinių kūrëjas, kurie gali laisvai judèti), K. kuriančių personažų apranga pilkos bei raudonos spalvos, kuri čia simbolizuoja svetima, iškart atpažistamą kaip pašalietị" (ten pat). Vaikai bei keletas paaugliu prisideda prie kafkiškosios atmosferos kūrimo: jie atstovauja keistam, chaotiškam pilies kanceliarijos darbui, juos galima įvardinti ir kaip kūrinio pasakotojo balsą.

Pilis ir jos žmonės nèra nei geri, nei blogi. Jie negailestingi prieglobsčio prašytojui K. Ir visiems kitiems gyventojams. Tačiau jie patys neatrodo gerai suvokiantys viso to prasmę. Vaikai, deklamuojantys F. Kafkos teksta, nesuteikia jam nepagristos 
prasmès. Tai galbūt vienintelis būdas parodyti, kad tai, kas $\langle\ldots>$ nebuvo suprantama, nerimą kelia ir šiandien (ten pat).

S. Holmo ir teatro NOVOFLOT sukurta F. Kafkos kūrinio adaptacija išryškina pagrindinę temą - susvetimèjimą. Ši tema apjungia du skirtingus kūrëjus romantizmo laikotarpio kompozitoriu
F. Schubertą ir egzistencializmo bei simbolizmo kryptims priskiriamą rašytoją F. Kafką. Rašytojo kūrinys apie pagrindini veikèją K., tačiau jame buvo ir kitų išsamiai atskleistų (pristatytų?) personažų, tuo tarpu ši sceninè adaptacija yra visa sukoncentruota (sutelkta i ) i K., viskas joje yra K.

\section{IŠVADOS}

Intertekstualus P. Ignatavičiaus spektaklis „Nuosprendis: Metamorfoze“", kurio pagrindiniais intertekstais tapo to paties rašytojo F. Kafkos kūriniai, adaptacijų studiju teoretiko D. Andrew klasifikacijoje užima ribinę poziciją tarp dviejų jo îvardintų tipų. Spektaklis gali būti priskiriamas skolinimosi (borrowing) tipui. Tokio sprendimo argumentai: režisierius nors ir jungia skirtingus kūrinius, bet jie yra to paties autoriaus, juose esančios idejos nedekonstruojamos, neparodijuojamos ar kitaip kardinaliai nekeičiamos, iš jų visų išgryninama pagrindinè tema tèvo ir sūnaus santykiai, - kuri neprieštarauja paties autoriaus kūrybai. Kita vertus, galima atrasti elementų, priartinančių ši spektakli prie susikirtimo (intersection). Pavyzdžiui, jungiant skirtingus kūrinius, kinta kūrinio veikejjai: kai kurie personažai igauna naujų savybių, kiti visai išnyksta. Nepaisant režisieriaus papildymų, įterpimų, trumpinimų, tekstų tema išlieka ta pati. Be to, spektaklyje jaučiamas kafkiškasis stilius.

Režisierius P. Capaldi savo filme iš novelès „Metamorfozè" pasiima tik vieną - pirmąji - sakini, siekia parodyti rašytoją bei pati novelès kūrimo procesą. Filmą, naudojantis D. Andrew sąvoko- mis (Andrew 1984), galima priskirti susikirtimo (intersection) adaptacijų tipui, nes čia režisierius jungia tris skirtingas medžiagas - novelę, rašytojo biografiją ir vieną žymiausių kino istorijos filmų. Ši filmą galima priskirti autoriaus Th. Leitcho dekonstrukcijos tipui, kuriam priklauso adaptacijos, reflektuojančios kūrybini procesą. Adaptacija pasižymi ironija keliais atžvilgiais. Pirmiausia pateikiamas požiūris i rašytojo kūrybos procesą pašiepiamos rašytojui kylančios idejos. Antra, prisimenant F. Kafkos neigiamą požiūrị i kiną, sprendimas novelès kūrimo procesą jungti su klasika tapusiu F. Capra kino filmu kuria dar vieną ironijos sluoksnį.

Lietuvos kino režisierius A. Puipa, adaptuodamas kitą F. Kafkos kūrini „Procesas", taip pat atsižvelgè i negatyvų rašytojo ir kino santykị, pagrindiniam veikèjui Josefui K. (vaid. K. Smoriginas) suteikdamas vizualų ivaizdi, itin artimą kino ikonai Ch. Chaplinui.

P. Ignatavičiaus ir P. Capaldi sukurtos adaptacijos skirtingose medijose - teatre ir kine - taip pat ikūnija ir skirtingus žanrus, interpretaciju rakursus. Spektaklyje dèmesys sutelkiamas į temą bei personažuc gilią psichologinę analizę, filmo reži- 
sierius susitelkė i pozityvesnę refleksiją. Abu kūrinius bei paties rašytojo kūrybą jungiantis dalykas - absurdas, priežastinio ryšio neapčiuopiamumas.

M. Haneke's ir S. Holmo kūriniuose adaptuojant tekstą išnaudojamos medijos galimybès. M. Haneke turëjo toki tiksla, apie kuri savo tekste yra kalbėjęs vienas pirmuju adaptacijų studijų lauko atstovų Andre Bazinas - paskatinti žiūrovus skaityti kūrinį. S. Holmas, pristatydamas „Pilies“ versiją šiuolaikinèje operoje, pateikè skirtingu mediju - literatūros, teatro, muzikos, vizualiųju me-

\section{Literatūra}

Andrew Dudley. 1984. Concepts in Film Theory. Oxford: Oxford university press.

Beard William, Smith-Prei Carrie. 2009. Adapting Alienation: Haneke's Vision of Kafka's The Castle (Das Schloss). The Films of Michael Haneke. Metro Cinema Society.

Croce F. Fernando. 2007. The Castle, SlantMagazine.com, 08 22. < http://www.slantmagazine. com/dvd/review/the-castle> [žiūrèta: 201911 19]

Foundas Scott. 2001. Interview: Michael Haneke: The Bearded Prophet of "Code Inconnu" and "ThePianoTeacher", IndieWare.com 12 04. <ttp:// www.indiewire.com/article/interview_michael_ haneke_the_bearded_prophet_of_code_inconnu_ and_the_piano_> [žiūrèta: 201911 19]

Ignatavičius Paulius. 2012. Nuosprendis: metamorfozè, OKT.lt <https://www.okt.lt/spektakliai/ nuosprendis-metamorfoze/>[žiūrèta: 201911 19] nų - sintezę ir menininkų F. Shuberto bei F. Kafkos jungini. Galima teigti, kad D. Andrew klasifikacijoje M. Haneke's adaptacija atstovauja gana retam ištikimos transformacijos tipui, tačiau filme nesiekiama dažniausiai neigiamai vertinamo pažodinio teksto perkèlimo, tai atliekama pasitelkiant kino kalba.

Trys iš keturių analizuotų adaptacijų pavyzdžių atsigręžia i papildomus kontekstus, dažniausiai i F. Kafkos kūrinius arba rašytojo biografija taip pat, siekiant kontrasto, naujo požiūrio i̇ rašytojo kūryba, pasitelkiami kiti kūriniai bei autoriai.

Kafka Franz. 1997. Laiškas tèvui. Vilnius: Vyturys, cit. iš: Bajarūnienè Jadvyga. Magiškoje tèvo nelaisvëje - F. Kafkos "Laiškas tèvui": 10.

Leitch Thomas. 2007. Film adaptation Eits discontents. Baltimore: The Johns Hopkins University Press.

Mansmann Nora. 2013. Das Schloss. Eine Winterreise von NOVOFLOT, Kultura extra, 0117. <:http://www.kultura-extra.de/musik/feull/ urauffuehrung_dasschloss_novoflot.php> [žiūrèta: 201912 14]

Munderzbakaitè Miglè. 2016. Rizika operoje sukuria sinergiją. Pokalbis su Svenu Holmu, Literatūra ir menas, 0527.

Woods Michelle. 2013. Kafka Translated: How Translators have Shaped our Reading of Kafka. New York: Bloomsbury Academic Press. 